ДК 336.226

$10.17213 / 2075-2067-2019-4-128-134$

\title{
РОЛЬ ИНФЛЯЦИОННОГО ФАКТОРА В ПОДДЕРЖАНИИ УСТОЙЧИВОСТИ НАЛОГОВЫХ ДОХОДОВ РОССИЙСКОЙ ФЕДЕРАЦИИ
}

\author{
(C) 2019 г. Д. А. Букланов
}

\section{Донской государственный технический университет, 2. Ростов-на-Дону}

Статья посвящена количественному исследованию влияния инфляиионного фактора на устойчивость налоговых доходов России. На основе анализа статистических трендов и коэффициентов эластичности сделаны выводы о противоречивом характере воздействия инфляции на устойчивость налоговых поступлений. В долгосрочном периоде рост цен выступает выраженным детерминантом увеличения номинальных налоговых доходов и салаживания их колебаний, в краткосрочном периоде - способствует увеличению флуктуачий поступлений отдельных налогов.

Ключевые слова: устойчивость налоговых поступлений; инфляция; индекс потребительских иеен; уравнение тренда; коэффициент эластичности.

The article is devoted to the quantitative study of the influence of the inflation factor on the stability of tax revenues in Russia. The analysis of statistical trends and elasticity coefficients leads to the conclusions about the contradictory nature of the impact of inflation on the stability of tax revenues. In the long term, price growth is a pronounced determinant of nominal tax revenues increasing and smoothing their fluctuations, in the short term - it contributes to an increase in fluctuations in individual tax revenues.

Key words: stability of tax revenues; inflation; consumer price index; trend equation; elasticity coefficient.

Современная рыночная экономика характеризуется выраженными инфляционными процессами, интенсивность которых варьирует в широких пределах, зависящих как от макроэкономической ситуации, так и от принятой парадигмы реализации денежно-кредитной политики. В настоящее время Российскую Федерацию можно отнести к странам со средним уровнем инфляции, значение которой в 2018 году составило 4,3\%, что больше, чем в США и большинстве стран Западной Европы, где прирост индекса потребительских цен не превысил 2,0\%.

Характеризуя причины возникновения инфляции, большинство экономистов сходятся во мнении, что основным ее источником является понижательная динамика курса национальной валюты, связанная с оттоком капитала, усилением санкционной риторики и зависимостью платежного баланса от цен на энергоносители [1]. Некоторые авторы делают акцент на обусловленности инфляции ростом издержек, при этом монетарным факторам отводится второстепенная роль. В частности, С.Н. Сайфиева делает такой вывод на основе сопоставления статистических показателей: индекс потребительских цен оказывается ниже индекса цен производителей, что позволяет констатировать инициацию инфляции издержек [2]. Симптоматично, что опережающая повышательная динамика прослеживается в сферах экономики, связанных с формированием цен на энергоносители и транспортные услуги, в результате чего 
происходит ускоренное развертывание инфляционной спирали.

Проблематика влияния инфляции на устойчивость налоговых поступлений в теоретических концепциях формулируется в двуедином качестве. В соответствии с описываемым в литературе «эффектом Оливера-Танци» налоговые поступления под воздействием инфляции сокращаются вследствие того, что налогоплательщики заинтересованы в постоянном откладывании исполнения налоговой обязанности на более поздний срок. Это ведет к фактическому «обесцениванию» налоговых доходов по причине наличия определенного временного лага между их начислением, фактической мобилизацией и осуществлением государственных расходов [3].

С другой стороны, инфляционная составляющая представляется одной из наиболее очевидных детерминант положительной динамики налоговых поступлений. Ее влияние реализуется посредством увеличения номинальных доходов налогоплательщиков, что в конечном итоге ведет к росту их налоговых обязательств без соответствующего изменения физического объема объектов налогообложения. Данный эффект, получивший название «эффекта Патинкина» [3], наиболее ярко проявляется для налогов на прибыль (доходы), база обложения которых в условиях инфляции индексируется максимально быстро.

В научных публикациях М. Ю. Малкиной и Р.В. Балакина на основе оригинальной детерминированной мультипликативной трехфакторной модели формирования налоговых доходов количественно идентифицирован «вклад» инфляции в их повышение, обеспечивший около 89\% их прироста в 20062014 гг. В соответствии с проведенными расчетами детализированное влияние на поступления отдельных налогов варьировало в пределах от 60 до 90\%: наименьшее воздействие выявлено для акцизов и государственной пошлины, исчисляемых по твердым ставкам, максимальное влияние прослеживается в случае налога на прибыль, т. к. «вклад» инфляционного фактора более чем в два раза превосходит сам прирост доходов по данному налогу [4].

Эконометрическое моделирование динамики налоговых поступлений с включением в качестве независимой переменной фактора инфляции, реализованное в статье А.И. Балаева, позволило определить эластичность налоговых доходов консолидированного бюджета по индексу потребительских цен, составившую 0,98 ед. Разложение вариации налоговых поступлений на «вклады» отдельных факторов привело к выводам о том, что от 63 до $67 \%$ их вариации обусловлено колебаниями цен на нефть, а на долю инфляции приходится лишь 1,3-2,2\% [5].

Таким образом, существующие оценки роли инфляционного фактора в формировании налоговых доходов крайне дифференцированы, что объясняется различиями в методах исследования: детерминированные модели способствуют завышению, а стохастические - занижению «вклада» инфляционной составляющей в динамику доходов.

Необходимым условием развернутого исследования влияния инфляции на устойчивость налоговых поступлений представляется предварительная идентификация тенденции их изменения во времени. Оценка динамики агрегированных налоговых доходов (без учета страховых платежей и таможенных пошлин) в абсолютном выражении позволяет констатировать наличие выраженного повышательного тренда, который с высокой степенью достоверности моделируется линейной или экспоненциальной зависимостью от времени (рисунок 1).

В соответствии с уравнением линейного тренда среднегодовой абсолютный прирост налоговых поступлений в исследуемый период составил 1027,2 млрд. рублей. Вместе с тем линейная функциональная зависимость основана на предположении об одинаковом изменении основной тенденции, что в случае с моделированием налоговых поступлений представляется избыточным упрощением ситуации.

Тенденции роста экономических показателей более корректно описываются экспоненциальной функцией, которая базируется на предположении о неравномерном характере изменения тренда, при котором каждое следующее значение определенным образом зависит от предыдущего. В нашем случае уравнение экспоненциального тренда налоговых доходов не только более точно соответствует диаграмме рассеяния, но и имеет более высокий коэффициент детерминации. Интерпретация коэффициентов регрессии 
позволяет рассчитать средний ежегодный темп роста налоговых поступлений, составивший 113,33\%.

Дефлирование налоговых доходов в постоянные цены 2002 года свидетельствует о значительном снижении интенсивности роста и более сильном влиянии кризисных явлений 2008-2009 гг. и 2014-2015 гг., в течение которых наблюдается сильная «просадка» налоговых поступлений и их менее интенсивное восстановление (рисунок 2).

Приведение налоговых поступлений к постоянным ценам существенно меняет общую картину динамики формирования налоговых доходов, которая значительно хуже поддается аппроксимации простыми функциями (использование полиномов третьего и четвертого порядка в данном случае нецелесообразно, поскольку их коэффициенты не имеют экономической интерпретации). Например, как линейная, так и экспоненциальная зависимости, судя по их коэффициентам детерминации, объясняют не более 70\% вариации налоговых поступлений. Анализ линейного тренда позволяет констатировать, что ежегодный прирост налоговых поступлений составил 139,12 млрд. руб. (против 1027,2 млрд. руб. при проведении расчетов в текущих ценах), а средние темпы роста, исходя из параметров экспоненциального трен- да, достигли лишь 103,99\% (против 113,33\% в номинальных ценах).

Детальный анализ поля корреляции на рисунке 2 демонстрирует наличие четырех микротрендов:

— первый — 2002-2008 гг. — период экономического роста в условиях высоких цен на энергоносители;

— второй - 2010-2012 гг. - восстановительный рост (так называемый «отскок») после резкого снижения доходов бюджета в 2009 году;

— третий — 2013-2016 гг. - период «торможения», в течение которого средние темпы роста экономики России отставали от среднемировых, к началу 2015 года страна вновь оказалась под воздействием сразу нескольких кризисов: структурного, циклического и внешних шоков (падение цен на нефть и введение финансовых санкций) [8];

— четвертый — 2016 г. — настоящее время - период оживления внешнеэкономической конъюнктуры, сопряженный с ростом эффективности налогового администрирования, что привело к подъему реальных налоговых поступлений по сравнению с уровнем 2012 года.

В целом результаты мобилизации налоговых поступлений в период 2002-2018 гг. характеризуются их ростом в 9,15 раза в аб-

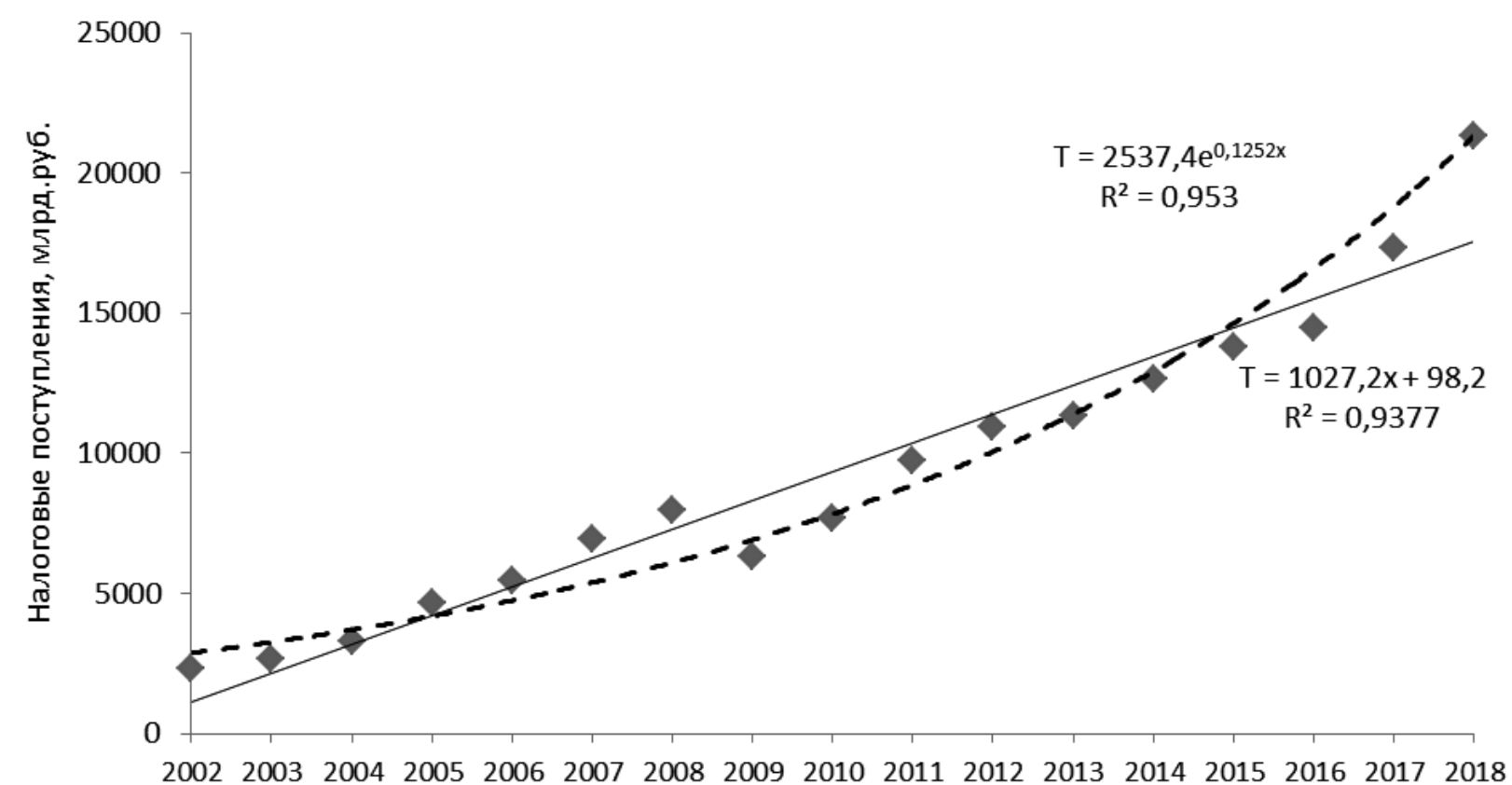

Рис. 1. Моделирование временного тренда налоговых поступлений РФ в период 2002-2018 гг. (рассчитано автором по [6]) 
солютном выражении и лишь в 2,36 раза в постоянных ценах 2002 года, что отражает, с одной стороны, инфляционную природу повышательного тренда, а с другой - позволяет рассматривать рост потребительских цен как один из инструментов стабилизации налоговых поступлений, который способствует сглаживанию их колебаний.

Для верификации гипотезы о преимущественно инфляционном характере наблюдаемого роста в работе исчислены и содержательно интерпретированы показатели эластичности налоговых доходов по индексу потребительских цен в период 2002-2018 гг. (таблица 1).

Анализ проведенных расчетов позволяет констатировать, что роль инфляционного фактора в формировании налогов бюджета является несколько преувеличенной, поскольку среднее значение эластичности налоговых поступлений по цене незначительно превышает единицу, т. е. увеличение инфляции способствует сопоставимому приросту доходов бюджета. Исключение составляет лишь налог на добычу полезных ископаемых, средняя эластичность которого составила 1,13 ед., достигая 1,3-1,5 ед. в периоды благоприятной внешнеэкономической конъюнктуры.
Несмотря на то, что обоснование зависимости налоговых доходов лишь от фактора инфляции представляется избыточным упрощением реальных процессов, можно прийти к выводу, что стабилизирующее действие последнего отчетливо идентифицируется как в условиях относительной стабильности, так и при резких флуктуациях экономической динамики, частично способствуя сокращению амплитуды колебаний налоговых поступлений. Так, в период экономических кризисов эластичность сокращается, что обеспечивает менее резкое «сжатие» доходов бюджетной системы: например, в кризисный 2009 год эластичность совокупных налоговых доходов по цене снизилась до 0,73 ед., в том числе за счет «провала» по НДПИ-0,57 ед. и налога на прибыль — 0,46 ед. Ускорение экономического роста, как правило, не только сопровождается инфляционным «перегревом», но и ведет к повышению коэффициента эластичности налогов по цене. В частности, в периоды роста 2005 года или восстановительного роста 2011, 2017-2018 гг. значение коэффициента эластичности находится в пределах 1,17-1,26 ед., что обеспечивает более интенсивную мобилизацию налоговых поступлений.

Сопоставление показателей эластичности по видам налогов позволяет сделать вывод

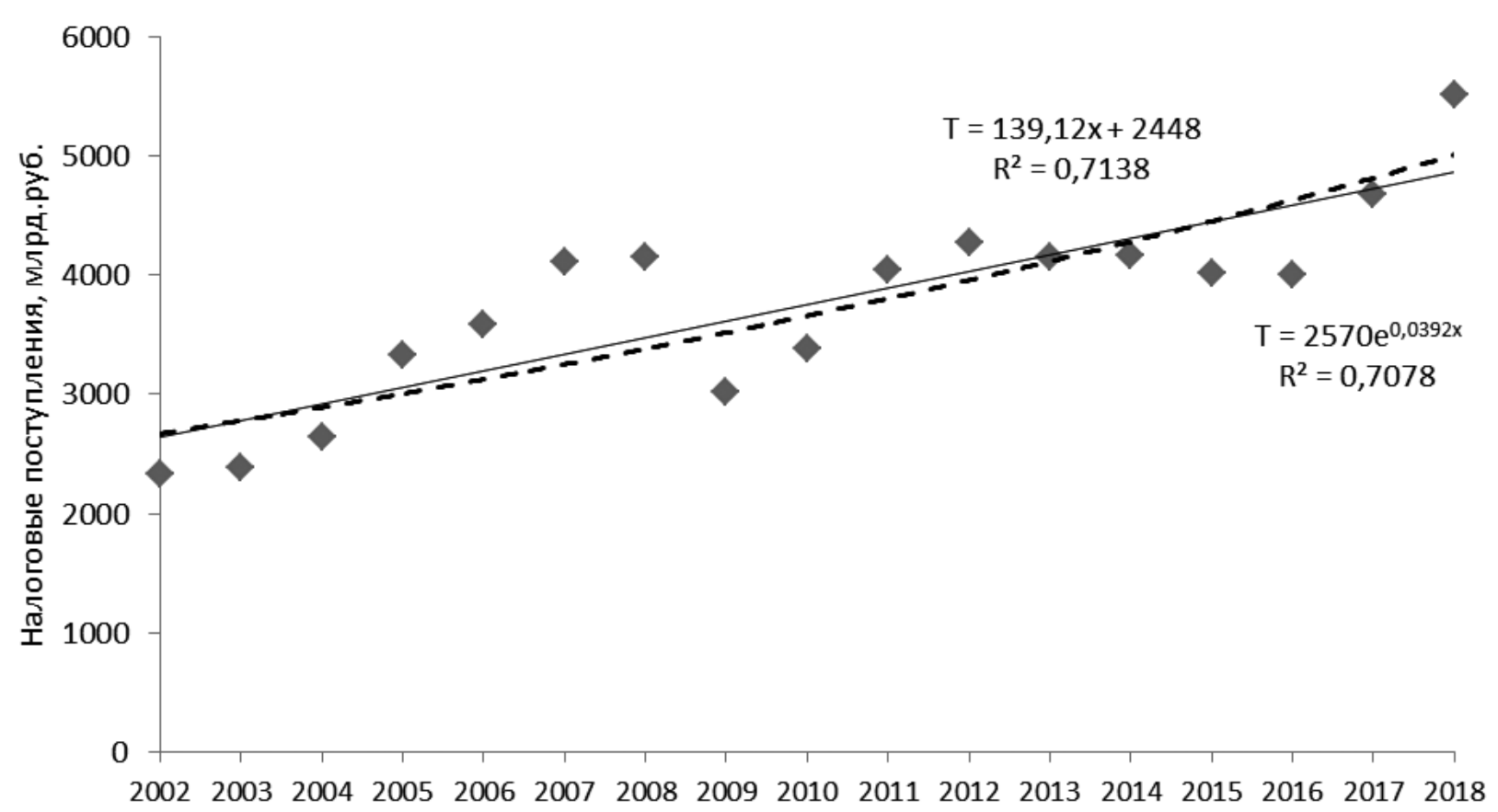

Рис. 2. Моделирование временного тренда налоговых поступлений РФ в постоянных ценах 2002 года в период 2002-2018 гг. (рассчитано автором по [6], [7]) 
о том, что косвенные налоги демонстрируют наименьшие средние значения (1,04-1,05 ед.), прямые налоги на прибыль и доход характеризуются более высокой эластичностью, а налоги на природные ресурсы обеспечивают максимальный опережающий «отклик» на изменение индекса потребительских цен. Флуктуации значений эластичности отдельных налогов в целом соответствуют интенсивности колебаний их темпов роста: наибольшая амплитуда изменений характерна для налога на прибыль и налогов на природные ресурсы, минимальная - для налогов на имущество.
В целом можно констатировать, что инфляция как выступает фактором повышательной динамики налоговых поступлений, так и способствует увеличению их устойчивости в перспективе. Об этом свидетельствуют средние значения коэффициентов эластичности налогов по индексу потребительских цен, которые всегда превышают единицу, что позволяет говорить о возникновении дополнительных инфляционных доходов бюджета. Симптоматично, что рост цен способствует опережающему увеличению налоговых доходов преимущественно в периоды экономи-

Таблица 1

Показатели эластичности налоговых доходов РФ по индексу потребительских цен в дискретной форме ${ }^{1}$

\begin{tabular}{|c|c|c|c|c|c|c|c|}
\hline \multirow[b]{2}{*}{ Годы } & \multicolumn{7}{|c|}{ Эластичность налоговых поступлений по индексу потребительских цен } \\
\hline & НДС & Акцизы & $\begin{array}{l}\text { Налог на } \\
\text { прибыль }\end{array}$ & НДФЛ & НДПИ & 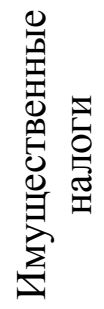 & 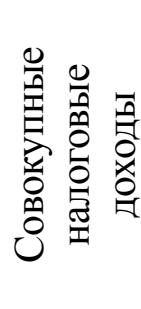 \\
\hline 2003 & 1,04 & 1,19 & 1,02 & 1,14 & 1,06 & 1,02 & 1,02 \\
\hline 2004 & 1,08 & 0,52 & 1,47 & 1,13 & 1,19 & 1,22 & 1,11 \\
\hline 2005 & 1,23 & 1,05 & 1,39 & 1,11 & 1,58 & 1,21 & 1,26 \\
\hline 2006 & 0,83 & 0,98 & 1,15 & 1,21 & 1,17 & 1,13 & 1,08 \\
\hline 2007 & 1,34 & 1,02 & 1,16 & 1,22 & 0,93 & 1,18 & 1,14 \\
\hline 2008 & 0,63 & 0,96 & 1,02 & 1,16 & 1,25 & 1,06 & 1,01 \\
\hline 2009 & 1,08 & 0,96 & 0,46 & 0,92 & 0,57 & 1,06 & 0,73 \\
\hline 2010 & 1,04 & 1,24 & 1,29 & 0,99 & 1,23 & 1,01 & 1,12 \\
\hline 2011 & 1,24 & 1,29 & 1,21 & 1,05 & 1,36 & 1,02 & 1,20 \\
\hline 2012 & 1,01 & 1,22 & 0,97 & 1,06 & 1,12 & 1,09 & 1,06 \\
\hline 2013 & 0,93 & 1,14 & 0,83 & 1,04 & 0,98 & 1,08 & 0,97 \\
\hline 2014 & 1,05 & 0,94 & 1,03 & 0,97 & 1,01 & 0,95 & 1,00 \\
\hline 2015 & 0,99 & 0,90 & 0,97 & 0,92 & 0,98 & 0,99 & 0,96 \\
\hline 2016 & 1,03 & 1,21 & 1,01 & 1,02 & 0,86 & 0,99 & 1,00 \\
\hline 2017 & 1,19 & 1,15 & 1,16 & 1,05 & 1,38 & 1,09 & 1,17 \\
\hline 2018 & 1,06 & 0,94 & 1,20 & 1,08 & 1,41 & 1,07 & 1,18 \\
\hline $\begin{array}{l}\text { Среднее } \\
\text { значение }\end{array}$ & 1,05 & 1,04 & 1,08 & 1,07 & 1,13 & 1,07 & 1,06 \\
\hline
\end{tabular}

1 Источник: рассчитано автором по [6], [7]. 
ческого подъема, в то время как кризисные явления способствуют резкому падению инфляционного прироста поступлений по отдельным налогам (речь идет об НДПИ и налоге на прибыль). Кроме того, периоды высокой инфляции, как правило, сопровождаются снижением коэффициентов эластичности вследствие «наложения» прочих кризисных факторов, нивелирующих проявление «эффекта Патинкина».

Переход к инфляционному таргетированию, реализуемый монетарными властями страны, начиная с 2014 года, вызывает ряд дискуссий, связанных, в первую очередь, с опасением дестимулирования инвестиций за счет повышения процентных ставок. Однако, как опыт развитых стран, так и результаты модельных расчетов российских ученых свидетельствуют о том, что принятая стратегия снижения инфляции в долгосрочной перспективе оказывает позитивное влияние на валовый выпуск за счет фиксации ситуации ценовой стабильности [9]. В этой связи режим инфляционного таргетирования с целевым ориентиром 4\%, закрепленный в денежно-кредитной политике России, с фискальной точки зрения представляется адекватным инструментом поддержания устойчивости доходов бюджета.

\section{Литература}

1. Российская экономика в 2018 году. Тенденции и перспективы. (Вып. 40) / под науч. ред. А.Л. Кудрина, С.Г. Синельнико-
ва-Мурылева. - М.: Изд-во Ин-та Гайдара, 2019. - $656 \mathrm{c}$.

2. Сайфиева С.Н. Влияние инфляции на величину налоговой нагрузки в отраслевом разрезе // Региональные проблемы преобразования экономики. - 2014. - №9. C. 99-109.

3. Шакирова Р.К. Инфляция, антиинфляционная политика и налоги: теория и практика// Финансы и кредит. — 2015. — №2 (626). C. 22-37.

4. Малкина М.Ю., Балакин Р.В. Факторный анализ динамики поступлений отдельных налогов в России в 2006-2014 гг. // Финансы и кредит. - 2016. - №32 (704). C. 16 .

5. Балаев А. И. Факторный анализ доходов российской бюджетной системы // Экономическая политика. — 2017. - Т. 12. №3. - С. 8-37.

6. Финансы России. 2018: Стат. сб. / Росстат. - М., 2018. - 439 с.

7. Индексы потребительских цен на товары и услуги по Российской Федерации в 1991-2019 гг. [Электронный ресурс] Режим доступа: http:/www.gks.ru/free_doc/ new site/prices/potr/tab-potr1.htm.

8. May B. A. Экономические кризисы в новейшей истории России // Экономическая политика. - 2015. - Т. 10. - №2. - С. 7-19.

9. Картаев Ф.С. Оценка влияния монетарной политики на экономический рост для различных групп стран // Финансы: теория и практика. - 2018. - Т. 22. - №1. - С. 50-63. 


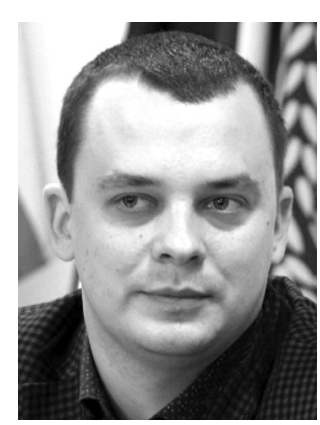

Букланов Дмитрий Александрович - ассистент кафедры «Экономика» Донского государственного технического университета.

Buklanov Dmitry Aleksandrovich - assistant of the Department of Economics of Don State Technical University.

344000 , г. Ростов-на-Дону, пл. Гагарина, 1

1 Gagarin sq., 344000, Rostov-on-Don, Russia

Тел.: +7 (863) 273-85-05; e-mail: buklanofff@mail.ru 